\title{
Bone marrow lymphocyte subsets in myelodysplastic syndromes
}

\author{
W Hilbe, W Eisterer, C Schmid, I Starz, H Silly, C Duba, C Ludescher, J Thaler
}

\begin{abstract}
Aim-To examine lymphocyte subsets in patients with myelodysplastic syndromes (MDS); and to correlate immunohistological variables with prognosis.

Methods-Bone marrow trephine biopsy specimens from 65 patients with MDS were immunophenotyped using a panel of antibodies. A minimum of 1000 cells from representative areas of marrow sections were counted at light microscopy. The association between immunohistological variables and prognosis was assessed.

Results-Compared with normal control marrows ( $n=23$ ) no major abnormalities of $T$ cells (CD3), $T$ cell subsets (CD4, CD8, CD25, TCR $\gamma / \delta)$ or natural killer cells (CD56, CD57) were seen in the 65 patients. In high risk MDS (RAEB, RAEB-t) $19 \%$ of the cases showed increased numbers of $B$ lymphocytes compared with none in the low risk group (RA, RARS) (p < 0.0090). Only percentages of $B$ cells above $3 \%$ significantly correlated with poor survival $(p=0.0121$ for CD19, $p=0.046$ for CD22).

Conclusions-The deviations in $\mathbf{T}$ lymphocyte counts seen in peripheral blood and in bone marrow aspirates could not be verified in bone marrow biopsy specimens.
\end{abstract}

\section{(F Clin Pathol 1994;47:505-507)}

Department of Internal Medicine, University of Innsbruck,

Anichstraße 35,

A-6020 Innsbruck,

Austria

W Hilbe

W Eisterer

$C$ Ludescher

J Thaler

Department of

Pathology, University

of Graz, Austria

C Schmid

Department of

Internal Medicine,

University of Graz

I Starz

H Silly

Institute for Medical

Biology and Human

Genetics, University of

Innsbruck

C Duba

Correspondence to:

Dr Wolfgang Hilbe

Accepted for publication

14 December 1993
The myelodysplastic syndromes (MDS) are a group of heterogeneous haematological disorders characterised by impaired maturation matopoiesis. On the basis of morphological criteria, the MDS are divided into five categories according to the French-AmericanBritish (FAB) Cooperative Group ${ }^{1}$ : refractory anaemia (RA), RA with ringed sideroblasts (RARS); RA with excess of blasts (RAEB); and RAEB in trans-formation (RAEB- $t$ ). Chronic myelomonocytic leukaemia (CMML) is considered by several authors ${ }^{2}$ to be a separate entity with a distinct clinical pattern. The incidence of transformation to acute myelogenous leukaemia is lower in patients with primary RA or RARS $(10 \%-15 \%)$ than in those with RAEB or RAEB-t (50\%-60\%). As a consequence, RA and RARS are defined as "low risk MDS" (LR-MDS) and RAEB and

Various abnormalities in the number or activity of lymphoid cells have been reported in patients with $M D S,-8$ including a decrease or dyspoiesis. This results in ineffective haeRAEB-t as "high-risk MDS" (HR-MDS). ${ }^{3}$ in $\mathrm{T}$ lymphocytes with a relative or even absolute increase in CD8 lymphocytes. This results in a reversed CD4:CD8 ratio, a decrease in B cells, ${ }^{5}$ and impaired natural killer cell activity. ${ }^{8}$ However, all these investigations were performed either on peripheral blood or on bone marrow aspirates. Despite the fact that bone marrow aspirates are inevitably contaminated by peripheral blood to some degree - up to $88 \%$ per volume-no clear definition of lymphocyte subsets in the bone marrow of patients with MDS is available. To our knowledge, only one study ${ }^{7}$ has used immunocytology to investigate lymphocyte subsets in bone marrow biopsy specimens. Although that study provided some evidence in support of an increased T8 fraction, it was limited because it used paraffin wax embedded and formalin fixed bone marrow sections. The aim of our study was to circumvent these problems and define lymphocyte subpopulations using cryostat sections from bone marrow trephines, allowing all currently available antibodies to be used. Furthermore, we investigated whether quantitative changes in defined lymphocytic groups in bone marrow correlate with clinical course and survival.

\section{Methods}

Iliac crest bone marrow trephines from 65 patients with MDS, as defined by the FAB classification, were collected between August 1984 and April 1993. Biopsy specimens were taken for diagnostic purposes and as treatment controls from the posterior iliac crest. The current diagnosis was: RA/RARS 18 cases; RAEB 24 cases; RAEB-t eight cases; CMML 15 cases. The 21 females and 44 males had a median age of 65 (range 2-87 years).

Bone marrow from 18 cases with AML and from 23 "normal" (leukaemia free) patients was examined as an internal control.

The most important clinical and haematological variables at the time of biopsy were evaluated: haemoglobin concentration; erythrocyte count; numbers of leucocytes, neutrophils, lymphocytes, monocytes, blast cells; platelets; previous treatment; current infections; chromosomal aberrations; FAB subtype changes; and survival. Clinical follow up was available in 53 cases and ranged from 0.5 to 89 months, with a median of 12 months. At the time of analysis, 15 (28\%) patients were alive and $38(72 \%)$ had died. The cause of death was related to bone marrow failure, infectious complications, or 
leukaemic transformation, but in many cases multiple factors were involved. Blast transformation was seen in $39 \%$ of the patients $(1 / 13$ RA/RARS; 8/12 RAEB; 4/5 RAEB-t, 2/8 CMML). Seven of the patients had secondary MDS subsequent to chemotherapy or radiotherapy.

For immunophenotypic analysis, bone marrow trephine biopsy specimens were prepared, as described before ${ }^{10}$; cryostat sections were covered with a panel of monoclonal antibodies CD3 (Leu4, Becton Dickinson, Mountainview, California, USA); CD4 (Leu3); CD8 (OKT8, Ortho Pharmaceutical Corp., Raritan, New Jersey, USA); CD19 (B4, Coulter Immunology, Hialeah, Florida, USA); CD22 (TO15, Dakopatts, Glostrup, Denmark); CD25 (IL2-R); CD56 (Leu19); CD57 (Leu7), Identi-T TCR $\gamma / \delta$ ( $\mathrm{T}$ cell Science, Cambridge, Massachusetts, USA). The slides were washed, incubated with the second step anti-mouse antibody (Dako Z 259 ), and incubated with the alkaline phosphatase antialkaline phosphatase complex (Dako D 651).

Slides were evaluated by two of the authors using a Leitz Dialux light microscope. To assess the fraction of immunopositive cells a minimum of 1000 cells from representative areas of marrow sections were counted.

Survival probability was estimated using the Kaplan-Meier product limit method. Statistical comparisons between curves were based on the log rank test. Survival was defined as the period from initial bone marrow biopsy to the date of last follow up or death. The correlation between immunohistological variables and prognosis was determined using Cox's proportional hazard model for covariate analysis of censored data.

\section{Results}

The immunohistological variables are summarised in the table. There were no significant differences between the percentages of immunopositive cells in the three main diag- nostic groups: MDS $v$ control $v$ AML. Nevertheless, values above the cutoff were found in some cases: CD19 of $\geqslant 3 \%$ : eight of 65 patients (two of 23 of the control group); CD22 of $\geqslant 3 \%$ : 11 of 65 (controls six of 23); CD3 of $\geqslant 10 \%: 18$ of 65 (controls six of 23); CD4 of $\geqslant 5 \%$ : 16 of 65 (controls eight of 23); CD8 of $\geqslant 5 \%$ : 18 of 65 (controls six of 23); CD57 of $\geqslant 0.5 \%$ : 14 of 65 (controls six of 23); CD56 of $\geqslant 0.5 \%$ : 34 of 65 (controls 15 of 23 ); TCR of $\geqslant 0.5 \%$ : 18 of 42 (controls six of 21); IL2 of $\geqslant 0.5 \%: 14$ of 42 (controls four of 22). In the high risk group $19 \%$ (six of 32) had more than 3\% CD 19 positive cells unlike the other groups (LRMDS 0 of 18, CMML 0 of 15) in which none of the patients had raised CD19 values $(p=$ $0.009)$. Similar results were seen for CD22, but were not significant.

Karyotypes were obtained from 35 patients. Chromosomal aberrations were seen in $18(51.4 \%)$ cases. Single abnormalities were present in 11 patients and multiple in seven cases. Only the presence of multiple chromosomal aberrations was associated with an unfavourable clinical course $(p<0.025)$. Most common changes were +8 (seven cases) and 5q- (four cases).

Significant prognostic indicators of survival were FAB classification ( $p=0.019)$, age (cutoff 65 years; $p=0.014$ ), haemoglobin (cutoff $100 \mathrm{~g} / \mathrm{l} ; \mathrm{p}=0.049$ ) and concomitant infection at time of biopsy $(p=0.029)$.

For the whole population $(n=53)$ two immunohistological variables were significant: CD19 (cutoff 3\%: $p=0.0121$ ) and CD22 (cutoff 3\%: $p=0.046$ ). All other histological and immunohistological variables failed to reach significance. Within the "low risk" group $(\mathrm{n}=16)$ natural killer cell $(\mathrm{p}=0.049)$ and TCR $\gamma / \delta(\mathrm{p}=0.015)$ count above $0.5 \%$ correlated with better clinical course. In the "high risk" group $(n=24)$ raised numbers of $B$, natural killer and TCR indicated a poorer survival (CD19: NS; CD22: $\mathrm{p}<0.03$; CD56: $\mathrm{p}<0.04 ; \mathrm{TCR} \gamma / \delta: \mathrm{p}<0.04)$. Within the CMML subgroup $(n=11)$, none of the

Immunohistological results of $R A / R A R S, R A E B, R A E B-t, C M M L, A M L$, and control groups

\begin{tabular}{|c|c|c|c|c|c|c|c|c|c|}
\hline \multirow[b]{2}{*}{ Antigen } & \multicolumn{3}{|c|}{$R A / R A S(n=18)$} & \multicolumn{3}{|c|}{$R A E B(n=24)$} & \multicolumn{3}{|c|}{$R A E B-t(n=8)$} \\
\hline & Median & Minimum & Maximum & Median & Minimum & Maximum & Median & Minimum & Maximum \\
\hline $\begin{array}{l}\text { CD } 19 \\
\text { CD } 22 \\
\text { CD } 3 \\
\text { CD } 4 \\
\text { CD } 8 \\
\text { CD } 57 \\
\text { CD } 56 \\
\text { TCR } \\
\text { CD 25 } \\
\text { CD4/CD8 } \\
\text { Age } \\
\text { Cellularity \% }\end{array}$ & $\begin{array}{l}1.9 \\
1.9 \\
10.0 \\
4 \cdot 8 \\
4.4 \\
0.1 \\
0.5 \\
0.4 \\
0.2 \\
1.04 \\
65 \\
45\end{array}$ & $\begin{array}{l}0.8 \\
0.5 \\
4.9 \\
2.6 \\
2.5 \\
0.0 \\
0.0 \\
0.0 \\
0.0 \\
0.51 \\
28 \\
20\end{array}$ & $\begin{array}{c}2 \cdot 6 \\
3 \cdot 6 \\
16 \cdot 7 \\
8 \cdot 5 \\
9 \cdot 4 \\
0 \cdot 7 \\
1 \cdot 5 \\
2 \cdot 2 \\
1 \cdot 3 \\
2 \cdot 45 \\
79 \\
90\end{array}$ & $\begin{array}{l}1 \cdot 9 \\
1 \cdot 7 \\
8 \cdot 3 \\
3 \cdot 5 \\
4 \cdot 0 \\
0 \cdot 0 \\
0 \cdot 5 \\
0 \cdot 3 \\
0 \cdot 1 \\
0 \cdot 93 \\
70 \\
60\end{array}$ & $\begin{array}{l}0.0 \\
0.0 \\
2 \cdot 7 \\
0.8 \\
1 \cdot 8 \\
0.0 \\
0.0 \\
0.0 \\
0.0 \\
0.43 \\
20 \\
30\end{array}$ & $\begin{array}{c}4 \cdot 1 \\
4 \cdot 3 \\
15 \cdot 0 \\
7 \cdot 2 \\
8 \cdot 5 \\
0 \cdot 7 \\
1 \cdot 2 \\
3 \cdot 0 \\
1 \cdot 3 \\
2 \cdot 57 \\
87 \\
90\end{array}$ & $\begin{array}{l}2 \cdot 9 \\
2 \cdot 3 \\
7 \cdot 5 \\
3 \cdot 9 \\
4 \cdot 6 \\
0 \cdot 1 \\
0 \cdot 3 \\
0 \cdot 5 \\
0 \cdot 3 \\
0 \cdot 96 \\
74 \\
78\end{array}$ & $\begin{array}{l}0.8 \\
0.7 \\
3.0 \\
0.9 \\
1 \cdot 1 \\
0.0 \\
0.0 \\
0.0 \\
0.0 \\
0.26 \\
51 \\
50\end{array}$ & $\begin{array}{c}5 \cdot 8 \\
4 \cdot 5 \\
13 \cdot 8 \\
6 \cdot 2 \\
6 \cdot 6 \\
0 \cdot 5 \\
1 \cdot 1 \\
0 \cdot 6 \\
1 \cdot 2 \\
4 \cdot 72 \\
82 \\
90\end{array}$ \\
\hline $\begin{array}{l}\text { CD } 19 \\
\text { CD } 22 \\
\text { CD } 3 \\
\text { CD } 4 \\
\text { CD } 8 \\
\text { CD } 57 \\
\text { CD } 56 \\
\text { TCR } \\
\text { CD } 25 \\
\text { CD 4/CD8 } \\
\text { Age } \\
\text { Cellularity \% }\end{array}$ & $\begin{array}{l}C M M L \\
1.5 \\
1.4 \\
5.7 \\
2.4 \\
2.1 \\
0.2 \\
0.5 \\
0.0 \\
0.0 \\
1.31 \\
68 \\
85\end{array}$ & $\begin{array}{l}\text { 5) } \\
0 \cdot 9 \\
0 \cdot 3 \\
1 \cdot 0 \\
1 \cdot 0 \\
0 \cdot 3 \\
0 \cdot 0 \\
0 \cdot 0 \\
0 \cdot 0 \\
0 \cdot 0 \\
0 \cdot 43 \\
2 \\
40\end{array}$ & $\begin{array}{c}2 \cdot 5 \\
10 \cdot 5 \\
12 \cdot 1 \\
4 \cdot 8 \\
6 \cdot 0 \\
0 \cdot 5 \\
1 \cdot 9 \\
0 \cdot 4 \\
0 \cdot 7 \\
8 \cdot 00 \\
82 \\
100\end{array}$ & $\begin{array}{l}A M L(n \\
1 \cdot 2 \\
1 \cdot 0 \\
8 \cdot 8 \\
3 \cdot 8 \\
2 \cdot 9 \\
0 \cdot 0 \\
0 \cdot 2 \\
0 \cdot 1 \\
0 \cdot 5 \\
1 \cdot 23 \\
58 \\
85\end{array}$ & $\begin{array}{l}0.2 \\
0.5 \\
4.0 \\
1.6 \\
1.0 \\
0.0 \\
0.0 \\
0.0 \\
0.0 \\
0.45 \\
20 \\
40\end{array}$ & $\begin{array}{c}2 \cdot 8 \\
3 \cdot 8 \\
16 \cdot 7 \\
6 \cdot 3 \\
7 \cdot 7 \\
1 \cdot 3 \\
1 \cdot 3 \\
1 \cdot 3 \\
2 \cdot 5 \\
3 \cdot 15 \\
80 \\
98\end{array}$ & $\begin{array}{l}\text { Controls } \\
1 \cdot 2 \\
2 \cdot 0 \\
8 \cdot 5 \\
4 \cdot 0 \\
3 \cdot 2 \\
0 \cdot 0 \\
0 \cdot 5 \\
0 \cdot 3 \\
0 \cdot 0 \\
1 \cdot 16 \\
50 \\
55\end{array}$ & $\begin{array}{l}\text { 23) } \\
0 \cdot 4 \\
0 \cdot 4 \\
2 \cdot 0 \\
1 \cdot 8 \\
0 \cdot 8 \\
0 \cdot 0 \\
0 \cdot 0 \\
0 \cdot 0 \\
0 \cdot 0 \\
0 \cdot 38 \\
21 \\
30\end{array}$ & $\begin{array}{r}3 \cdot 8 \\
3 \cdot 5 \\
14 \cdot 6 \\
10 \cdot 7 \\
8 \cdot 6 \\
1 \cdot 0 \\
2 \cdot 6 \\
6 \cdot 0 \\
1 \cdot 0 \\
5 \\
72 \\
95\end{array}$ \\
\hline
\end{tabular}


immunohistological variables correlated with survival.

In multiple regression analysis none of the immunohistological variables was of prognostic value.

\section{Discussion}

Abnormalities in lymphocyte subsets in the peripheral blood and bone marrow aspirates of patients with MDS have been shown before. ${ }^{4-68}$ Furthermore, Kitagawa et al reported significant changes in bone marrow lymphoid cells in paraffin wax embedded bone marrow biopsy specimens. Increased T8 numbers and a reduction in total numbers of lymphoid cells correlated with progression to overt leukaemia. In that study, however, $T$ cell values were estimated indirectly with the polyclonal rabbit antibody against S-100 protein, which, the authors report, was expressed on both suppressor $\mathrm{T}$ cells and histiocytes. Using immunohistological analysis of bone marrow cryostat sections, we were unable to show significant differences in lymphocyte subsets between MDS $(n=65)$ and a control group $(n=23)$. The only minor changes in bone marrow lymphocyte subsets observed in our study contrast sharply with the pronounced differences reported in peripheral blood.468 This discrepancy might be explained by redistribution between peripheral blood and other tissues, such as lymph nodes or spleen, while bone marrow remains unaffected. These largely normal lymphocyte values further support the findings of recent publications, which have shown that lymphocytes are polyclonal in most cases of MDS. ${ }^{3}$

The second part of this study investigated the prognostic implication of bone marrow lymphocyte counts compared with established prognostic variables for this disease. The following were significant: age of 65 years and over; previous infections; a haemaglobin concentration of less than $100 \mathrm{~g} / \mathrm{l}$; FAB subtype; and multiple cytogenetic aberrations. For lymphocyte subsets, only B cell markers defined a small subgroup with poor survival ( $>$ $3 \%$ positive cells, $\mathrm{p}=0.0121)$. All the other immunophenotypical variables (CD3, CD4, $\mathrm{CD} 8, \mathrm{CD} 25, \mathrm{TCR} \gamma / \delta, \mathrm{CD} 56, \mathrm{CD} 57)$ failed to predict outcome.

All in all, the deviations of lymphocyte subsets seen in the peripheral blood and bone marrow aspirates could not be verified in the bone marrow biopsy specimens.

This work was supported by the "Forschungsfonds der Oberwasserlechner and Annemarie Maneschg for their excel lent technical assistance.

1 Bennet JM, Catovsky D, Daniel MT, et al. Proposals for the classification of the myelodysplastic syndromes. $\mathrm{Br} F$ Haematol 1982;51:189-99.

2 Fenaux P, Jouet JP, Zandecki $M$, et al. Chronic and subacute myelomonocytic leukemia in the adult: a report of 60 cases with special reference to prognostic factors. $\operatorname{Br} \mathcal{F}$ Haematol 1987;65:101-6.

3 Willemze R, Fibbe WE, Falkenburg JHF, Kluin-Nelemans JC, Kluin PM, Landegent JE. Biology and treatment of myelodysplastic syndromes - developments in the past decade. Ann Hematol 1993;66:107-15.

4 Bynoe AG, Scott CS, Ford P, Roberts BE. Decreased T helper cells in the myelodysplastic syndromes. $B r f$ Haematol 1983;54:97-102.

5 Hokland P, Kerndrup G, Griffin JD, Ellegaard J. Analysis of leukocyte differentiation antigens in blood and bone marrow from preleukemia (refractory anemia) patients marrow from preleukemia (refractory anemia) patien

6 Baumann MA, Milson TJ, Patrick CW, Libnoch J, Keller R. Immunoregulatory abnormalities in myelodysplastic Ryndromes. Am $₹$ Hematol $1986 ; 22: 17-26$.

7 Kitagawa M, Kamiyama R, Takemura T, Kasuga T. Bone marrow analysis of the myelodysplastic syndromes: marrow analysis of the myelodysplastic syndromes: to the evolution of overt leukemia. Virchows Arch (Cell Pathol) 1989;57:47-53.

8 Takaku S, Takaku F. Natural killer cell activity and preleukemia. Lancet $1981 ;$;i: 1178 .

9 Clark P, Normansell DE, Innes DJ, Hess CE. Lymphocyte subsets in normal bone marrow. Blood 1986;67:1600-6.

10 Thaler J, Denz H, Gattringer C, et al. Diagnostic and prognostic value of immunohistological bone marrow examination: results in 212 patients with lymphoproliferative disorders. Blut 1987;54:213-22. 